Geology

June 2016, Volume 44 Issue 6 Pages 423-426

http://dx.doi.org/10.1130/G37585.1

http://archimer.ifremer.fr/doc/00345/45668/

(c) 2016 Geological Society of America. For permission to copy, contact

editing@geosociety.org.

\title{
Tectonic regime controls clustering of deformation bands in porous sandstone
}

\author{
Soliva Roger ${ }^{1}$, Ballas Gregory ${ }^{2}$, Fossen Haakon ${ }^{3,4}$, Philit Sven ${ }^{1}$
}

${ }^{1}$ Univ Montpellier, Geosci Montpellier, Campus Triolet,CC060,PI Eugene Bataillon, F-34095 Montpellier 05, France.

${ }^{2}$ Inst Francais Rech Exploitat Mer, F-29280 Plouzane, France.

${ }^{3}$ Univ Bergen, Dept Earth Sci, Allegaten 41, N-5007 Bergen, Norway.

${ }^{4}$ Univ Bergen, Museum Nat Hist, Allegaten 41, N-5007 Bergen, Norway.

\begin{abstract}
:
Porous sandstones tend to deform by the formation of low-permeability deformation bands that influence fluid flow in reservoir settings. The bands may be distributed or localized into clusters, and limited recent data suggest that tectonic regime may exert control on their distribution and clustering. In order to explore this suggestion, we performed a synthetic analysis based of 73 sets of bands, including 22 new sets measured for a reverse Andersonian regime that fill the important gap in data for this context. We find a surprisingly strong correlation between clustering and tectonic regime, where bands clearly are more distributed in the reverse regime compared to the normal regime. Together with the observed band distributions, capillary pressure data show evidence that efficient membrane seals are expected for extension, whereas pervasive permeability anisotropy is expected for contraction. Such a basic new rule concerning tectonic regime is very useful for assessment of reservoir properties where deformation bands are common but below seismic resolution.
\end{abstract}


Publisher: GSA

Journal: GEOL: Geology

DOI:10.1130/G37585.1

\section{INTRODUCTION}

25 Tectonic deformation in porous sandstones generally produces cataclastic

26 deformation bands in which grain crushing, sliding and rolling take place (Aydin, 1978;

27 Fossen et al., 2007). The result is typically grain size reduction that causes porosity loss

28 and reduction of permeability by up to 6 orders of magnitude (Fossen and Bale, 2007;

29 Ballas et al., 2015). Different classes of cataclastic deformation bands have been

30 recognized as a function of their relative amount of shear to compaction, including shear

31 bands (SB), compactional shear bands (CSB), shear enhanced compaction bands (SECB)

32 and pure compaction bands (PCB) (Eichhubl et al., 2010; Soliva et al., 2013). Some of

33 their properties, such as their displacement-length scaling relationship (Schultz et al.,

34 2008), degree of cataclasis, petrophysical properties (Ballas et al., 2014) and spatial

35 distribution (Fortin et al., 2005; Saillet and Wibberley, 2010) seem directly linked to such

36 differences in kinematics. Identifying the internal and external factors controlling such

37 differences in band kinematics could then be of first-order importance for sandstone

38 reservoir characterization.

39 Both mechanical tests and field data in porous sandstones suggest that many

40 factors, including grain size, porosity, proximity to faults, segmentation, burial depth, and

41 potentially also fluid pressure, are thought to influence the spatial distribution of

42 deformation bands and their relative amount of shear to compaction (e.g., Wibberley et

43 al., 2007; Solum et al., 2010; Nicol et al., 2013; Soliva et al., 2013; Ballas et al., 2014). In

44 this paper we inspect the role of tectonic regime on the spatial distribution of deformation 
Publisher: GSA

Journal: GEOL: Geology

DOI:10.1130/G37585.1

45 bands with new data collected from 22 outcrops in contractional settings in California,

46 Nevada, France, Germany and Taiwan. This allows for a sound synthetic analysis of band

47 distribution in reverse regime compared to data in normal regimes collected from the

48 literature. We briefly discuss the origin of the observed general trend and implications for

49 sandstone reservoirs.

\section{GEOLOGIC SETTINGS}

51 Band frequency data (number of bands per meter) were measured in Nevada in

52 the fine to medium grained porous Jurassic Aztec Sandstone (Fossen et al., 2015). This

53 unit has been involved in the Cretaceous Sevier orogeny, with the east to southeast

54 transport of the Muddy Mountain thrust sheet. Data have been collected from 3 principal

55 sites, one in the Buffington window and the two others in the Valley Of Fire State Park.

56 In California, data were collected from oil-filled porous sandstones of the Edna

57 Member of the Mio-Pliocene Pismo Basin (Antonellini et al., 1999). This basin occupies

58 a syncline limited by the Edna thrust fault to the northeast. Layers containing deformation

59 bands show a wide range in grain size (fine-grained sand to gravel). Measurements were

60 made on one outcrop but are separated into 3 sets because of the different band

61 distributions observed in the different layers.

62 In France we measured band sets in the porous Cretaceous sandstones of the

63 South East Basin (Ballas et al., 2014). These marine sandstones have been folded and

64 faulted during the N-S Paleocene-Eocene Pyrenean shortening, and data from 8 outcrops

65 are reported here for host rocks showing medium to coarse grain sizes.

66 Data from Germany were collected from the Subhercynian Alpine basin in the

67 medium-size porous sandstones of the lower Cretaceous Involutus and Heidelberg 
Publisher: GSA

Journal: GEOL: Geology

DOI:10.1130/G37585.1

68 formations (Klimczak and Schultz, 2013). This basin is folded and mainly faulted at its

69 Southwestern border by the Harz Mountain thrust. Data reported in this paper are from 4

70 outcrops observed at different places in the basin, with one outcrop very close to the Harz

71 thrust and 3 others relatively far from the thrust $(>2 \mathrm{~km})$.

72 Cataclastic bands from Taiwan are located on the East Coast (Shihtiping), in fine-

73 to coarse-grained volcanic-tuff sandstones. These deposits are related to the formation of

74 the Coastal Range due to the arc-continent collision $\sim 7$ million years ago. A N-S striking

75 fold affects these deposits and 2 band sets were measured in the site.

\section{BAND SET GEOMETRY, FREQUENCY AND CLUSTERING}

\section{$77 \quad$ Method}

78 Because many workers have counted the number of individual bands per meter,

79 we proceed in the same way, using a tape ruler along outcrops, to allow for a global data

80 synthesis. Most data sets from the Andersonian normal stress regime are acquired along

81 scan lines oriented along the direction of maximum extension (X-axis of the strain

82 ellipsoid). For the new measurements provided for the Andersonian reverse stress regime,

83 we counted the bands along a scan line oriented along the direction of maximum

84 shortening (Z-axis).

\section{Band Set Geometry}

86 Outside of fault zones, cataclastic deformation bands forming reverse band sets

87 are generally pervasive sets of SECBs or CSBs. SECBs generally show no visible

88 displacement in the field and outcrop as conjugate sets that intersect only in some parts of

89 the outcrops (Fig. 1a). CSBs generally outcrop as regular mesh-like geometries of

90 conjugate crosscutting bands (Fig. 1b), along which reverse sense displacement of a few 
Publisher: GSA

Journal: GEOL: Geology

DOI:10.1130/G37585.1

91 centimeters can be observed. Both types of band sets are very rare in fine sandstones, and

92 are generally restricted to specific layers of medium to coarse porous sandstone. Within

93 the deformed layers, the spatial distribution of the bands is extensive, generally over

94 entire outcrop exposures (tens to a hundred meters) with more or less evenly spaced

95 bands (Figs. 1a and 1b). Note however that SBs organized as clusters can also be

96 observed in reverse regime, but specifically located within fault zones (see Figure 1e

97 Subhercynian).

98 Bands in the normal regime are typically CSBs and SBs clustered around normal

99 faults, defining damage zones. Damage zones are characterized by a steep increase in

100 band density toward a main fault surface, which is located along or within a central

101 cluster zone (Figs. 1c and 1d). In addition, clusters can also occur as incipient fault

102 structures far from established fault surfaces. SBs in the clusters are spaced a few

103 millimeters or centimeters apart, and generally oriented subparallel to the fault. Bands

104 can form parallel or conjugate sets, branching or as mutually crosscutting structures (Fig.

105 1b). These SBs can show centimeter- to decimeter-scale displacements and generally

106 display more intense cataclasis than CSBs and SECBs.

107 Histograms of number of bands per meter are shown in Figure 1e for some of the

108 most representative reverse band sets. These graphs show nearly homogeneous to

109 polymodal distribution with some modes that are located at places where few faults or

110 ladder structures are observed (see Schultz and Balasko, 2003 for definition of ladder

111 structure). For all the reverse band sets reported in the literature (see Figure 2 for

112 references), the mean value of bands per meter is 12 , with a standard deviation of 9.6.

113 The spatial distribution is particularly heterogeneous in outcrops showing variations in 
Publisher: GSA

Journal: GEOL: Geology

DOI:10.1130/G37585.1

114 lithology such as the case of the Pismo Basin (Fig. 1e). Relatively high values of bands

115 per meter are observed in medium-grained units (generally $>10$ bands $/ \mathrm{m}$ ), while lower

116 band frequencies are observed in coarse-grained units (generally $<10$ bands $/ \mathrm{m}$ ), and few

117 bands are observed in the sand matrix of gravel units. Fine sandstones, cemented

118 sandstones or other low-porosity rock layers are devoid of SECBs or CSBs.

119 The distribution of normal sense bands per meter appears Gaussian or Log-

120 Normal like; see Figure $1 \mathrm{f}$ for some of the most representative normal band sets

121 measured. These modal distributions generally show a progressive increase in band

122 density to a maximum value (cluster), into which bands are very closely packed (Fig. 1c).

123 An asymmetric distribution (Log-Normal distribution type) generally reflects the

124 juxtaposition of differently damaged units around a fault surface. For all the normal band

125 sets collected from the literature (Fig. 2), the maximum number of bands per meter

126 reaches the value of 161 . Also note that zones devoid of bands are frequently reported on

127 the graphs presented in Figure 1f.

\section{Data Synthesis Analysis}

129 We have synthetized all the band density data obtained from our own field work

130 and from the literature, altogether 24, 47 and 2 band sets from the reverse, normal and

131 strike-slip regime, respectively. These 73 sets represent a total of 27074 bands recorded

132 along scan lines from sandstones showing a wide range in porosity $(18.6-35.14 \%)$,

133 grain size $(0.24 \mathrm{~mm}$ in diameter to gravels), burial depth $(0.3-2.5 \mathrm{~km})$ and diagenetic

134 context.

135 To precisely examine the relative spatial distribution of bands of all sets together, 136 we calculate the "cluster factor" (Wibberley et al., 2007) for each set. This parameter is a 
Publisher: GSA

Journal: GEOL: Geology

DOI:10.1130/G37585.1

137 standard deviation-type function describing the degree of clustering within a given band

138 set along a scan line. The "cluster factor" is defined as:

$$
C f=\sqrt{\left(\frac{\sum f_{i}^{2}}{\Sigma f_{i}}-f_{a v}\right)}
$$

140 in which $f_{i}$ is the number of bands encountered per meter of scan line, $i$ represents

141 the $i^{\text {th }}$ meter interval along the scan line, and $f_{a v}$ is the average band frequency for the

142 entire scan line. For all the band sets collected and measured, this factor varies between

1430.47 and 8.78 , where 8.78 corresponds to the highest band clustering and 0.47 is the most 144 even band distribution.

145 A global data analysis shows a clear difference between reverse and normal band

146 sets with respect to spatial distribution. Figure 2 presents all band sets measured by us

147 and collected from the literature as a function of the cluster factor and the maximum

148 value of bands per meter. This graph reveals that reverse band sets (black dots) have low

149 cluster factor, but also low values of maximum band per meter as compared to normal

150 band sets. Reverse band sets have cluster factor values between 0.4 and 2.8 , with $\sim 25 \%$

151 of the sets having values $>2$, and a maximum band per meter ranging from 6 to 67 , with

$152 \sim 70 \%$ of the sets having values $<30$. In contrast, normal band sets have cluster factor

153 values between 1.4 and 8.8 , with $>80 \%$ having values higher than 2 , and maximum band

154 per meter ranging from 9 to 161 , with $\sim 70 \%$ having values $>30$. This synthetic data set

155 analysis shows two different and little-overlapping graphical domains for reverse and

156 normal band sets, revealing that sets formed in the reverse tectonic regime (contraction)

157 are generally more spatially distributed than sets formed in the normal tectonic regime

158 (extension). Large cluster factor values seem possible also for the strike-slip regime. 
Publisher: GSA

Journal: GEOL: Geology

DOI:10.1130/G37585.1

159 Beyond the fact that the amount of strike-slip data has no significant statistical weight,

160 this low amount of data allows questioning the extent of their occurrence in porous

161 sandstones.

\section{DISCUSSION}

163 The global data set presented in Figure 2, clearly shows that reverse bands are

164 more spatially distributed than normal bands, which are characterized by more clustered

165 distributions. This difference in organization reveals that tectonic regime is a prominent

166 factor for the distribution of deformation bands in porous sandstone. However, the

167 presence of faults and even primary lithologic heterogeneities seem to be factors that can

168 influence the distribution of bands in reverse band sets (Fig. 1e), but do not control the

169 general trend. On the other hand, spatially distributed band sets have also been observed

170 in extensional settings, but in specific settings such as in relay zones (e.g., Davatzes and

171 Aydin, 2003, open dot noted 4 in Fig. 2) or in cases where strong lithological contrasts

172 impede the propagation of SBs (Schultz and Fossen, 2002).

173 This influence of tectonic context can be explained by the difference in stress

174 paths occurring in sandstone under normal and reverse tectonic regimes (Soliva et al.,

175 2013). Indeed, relatively low mean stress inherent to tectonic extension lead to a

176 localized Byerlee-type cataclastic-shear behavior, whereas high mean stress promoted by

177 tectonic contraction lead to distributed compactional/cataclastic behavior (see

178 supplementary material for the mechanical explanation and Wong and Baud, 2012 for the

179 behavior of porous sandstones). This analysis therefore suggests that remote tectonic

180 stress has a stronger influence on band distribution in general than local stress, such as

181 provided by reactivation of inherited faults, layering or fault segmentation. 
Publisher: GSA

Journal: GEOL: Geology

DOI:10.1130/G37585.1

Because deformation bands are well known to be subseismic structures, the

183 exposed evidences of different strain localization, together with differences in

184 petrophysical properties between shear-dominated and compaction-dominated bands,

185 provide important conclusions for the management of sandstone reservoirs. Recent data

186 compilation shows that permeability is significantly lower into shear-dominated bands

187 compared to compaction-dominated bands (Ballas et al., 2015), but rather than

188 permeability, capillary pressure is an efficient indicator of the ability of a fault to act as a

189 barrier to fluid flow over geologic time. A new compilation of capillary pressure and

190 porosity (Fig. 3), measured both in reverse and normal band sets sampled in the field,

191 clearly shows that the capillary pressure is generally higher for normal bands than for

192 reverse bands (see supplementary material for method of capillarity calculation). This

193 implies the presence of seals and stronger permeability anisotropy in porous sandstone

194 reservoirs affected by tectonic extension than contraction. Such basic new rules of

195 tectonic control of fluid flow and compartmentalization in sandstone reservoir is of major

196 importance for both economic fluid exploration/production and $\mathrm{CO}_{2}$ storage planning.

197 ACKNOWLEDGMENTS

198 This work was funded by a 2010-2014 project between Areva and the Laboratory

199 Géosciences Montpellier and Grant from Ecole Doctorale Sibaghe (University of

200 Montpellier). We thank Pr. Chia-Yu Lu from the National Taiwan University for his help

201 in the field, associate editor James Spotila, Stephen Laubach and two anonymous

202 reviewers for their constructive comments.

203 REFERENCES CITED 
Publisher: GSA

Journal: GEOL: Geology

DOI:10.1130/G37585.1

204 Antonellini, M.A., Aydin, A., and Orr, L., 1999, Outcrop-aided characterization of a

205 faulted hydrocarbon reservoir: Arroyo Grande oil field, California, USA, in

206 Haneberg, W.C., Mozley, P.S., Moore, J.C., and Goodwin, L.B., eds., Faults and

207 Subsurface Fluid Flow in the Shallow Crust: Washington, D.C., American

208 Geophysical Union Geophysical Monograph 113, p. 7-26,

209 doi:10.1029/GM113p0007.

210 Aydin, A., 1978, Small faults formed as deformation bands in sandstone: Pure and

211 Applied Geophysics, v. 116, p. 913-930, doi:10.1007/BF00876546.

212 Ballas, G., Soliva, R., Benedicto, A., and Sizun, J.-P., 2014, Control of tectonic setting

213 and large-scale faults on the basin-scale distribution of deformation bands in porous

214 sandstone (Provence, France): Marine and Petroleum Geology, v. 55, p. 142-159,

215 doi:10.1016/j.marpetgeo.2013.12.020.

216 Ballas, G., Fossen, H., and Soliva, R., 2015, Factors controlling permeability of

217 cataclastic deformation bands and faults in porous sandstone reservoirs: Journal of

218 Structural Geology, v. 76, p. 1-21, doi:10.1016/j.jsg.2015.03.013.

219 Davatzes, N.C., and Aydin, A., 2003, Overprinting faulting mechanisms in high porosity

220 sandstones of SE Utah: Journal of Structural Geology, v. 25, p. 1795-1813,

221 doi:10.1016/S0191-8141(03)00043-9.

222 Eichhubl, P., Hooker, J., and Laubach, S.E., 2010, Pure and shear-enhanced compaction

223 bands in Aztec Sandstone: Journal of Structural Geology, v. 32, p. 1873-1886,

224 doi:10.1016/j.jsg.2010.02.004

225 Fortin, J., Shubnel, A., and Guégen, Y., 2005, Elastic wave velocities and permeability

226 evolution during compaction of Bleurswiller Sandstone: International Journal of 
Publisher: GSA

Journal: GEOL: Geology

DOI:10.1130/G37585.1

Rock Mechanics and Mining Sciences, v. 42, p. 873-889,

doi:10.1016/j.ijrmms.2005.05.002.

Fossen, H., and Bale, A., 2007, Deformation bands and their influence on fluid flow: The doi:10.1306/07300706146.

232 Fossen, H., R.A. Schultz, Z.K. Shipton, and K. Mair, 2007, Deformation bands in sandstone: a review: Journal of Geological Society, London, v. 164, p. 755-769, doi: 10.1144/0016-76492006-036.

235 Fossen, H., Zuluaga, L.F., Ballas, G., Soliva, R., and Rotevatn, A., 2015, Contractional

236 deformation of porous sandstone: Insights from the Aztec Sandstone in the footwall to the Sevier-age Muddy Mountains thrust, SE Nevada, USA: Journal of Structural Geology, v. 74, p. 172-184, doi:10.1016/j.jsg.2015.02.014.

240 Subhercynian Cretaceous Basin, Germany: International Journal of Earth Sciences,

241 v. 102 , p. 121-138, doi:10.1007/s00531-012-0794-z.

242 Nicol, A., Childs, C., Walsh, J.J., and Schafer, K.W., 2013, A geometric model for the 243 formation of deformation band clusters: Journal of Structural Geology, v. 55, p. 21-

$244 \quad 33$, doi:10.1016/j.jsg.2013.07.004.

245 Saillet, E., and Wibberley, C.A.J., 2010, Evolution of cataclastic faulting in high-porosity

246 sandstone, Bassin du Sud-Est, Provence, France: Journal of Structural Geology,

$247 \quad$ v. 32, p. $1590-1608$, doi:10.1016/j.jsg.2010.02.007. 
Publisher: GSA

Journal: GEOL: Geology

DOI:10.1130/G37585.1

248 Schultz, R.A., and Balasko, C.M., 2003, Growth of deformation bands into echelon and

249 ladder geometries: Geophysical Research Letters, v. 30, p. 2033-2036,

250 doi:10.1029/2003GL018449.

251 Schultz, R.A., and Fossen, H., 2002, Displacement-length scaling in three dimensions:

252 The importance of aspect ratio and application to deformation bands: Journal of

253 Structural Geology, v. 24, p. 1389-1411, doi:10.1016/S0191-8141(01)00146-8.

254 Schultz, R.A., Soliva, R., Fossen, H., Okubo, C., and Reeves, D.M., 2008, Dependence of

255 displacement-length scaling relations for fractures and deformation bands on the

256 volumetric changes across them: Journal of Structural Geology, v. 30, p. 1405-1411,

257 doi:10.1016/j.jsg.2008.08.001.

258 Soliva, R., Schultz, R.A., Ballas, G., Taboada, A., Wibberley, C.A.J., Saillet, E., and

259 Benedicto, A., 2013, A model of strain localization in porous sandstone as a function

260 of tectonic setting, burial and material properties; new insight from Provence (SE

261 France): Journal of Structural Geology, v. 49, p. 50-63,

262 doi:10.1016/j.jsg.2012.11.011.

263 Solum, J.G., Brandenburg, J.P., Naruk, S.J., Kostenko, O.V., Wilkins, S.J., and Schultz,

264 R.A., 2010, Characterization of deformation bands associated with normal and

265 reverse stress states in the Navajo Sandstone, Utah: The American Association of

266 Petroleum Geologists Bulletin, v. 94, p. 1453-1475, doi:10.1306/01051009137.

267 Wibberley, C.A.J., Petit, J.-P., and Rives, T., 2007, The mechanics of fault distribution

268 and localization in high-porosity sands, Provence, France, in Lewis, H., and Couples,

269 G.D., eds., The relationship between damage and localization: Geological Society,

270 London, Special Publications 289, p. 19-46, doi:10.1144/SP289.3. 
Publisher: GSA

Journal: GEOL: Geology

DOI: $10.1130 / \mathrm{G} 37585.1$

271 Wong, T.-f., and Baud, P., 2012, The brittle-ductile transition in porous rock: A review:

272 Journal of Structural Geology, v. 44, p. 25-53, doi:10.1016/j.jsg.2012.07.010.

274 FIGURE CAPTIONS

275

276 Figure 1. Examples of geometry and spatial distribution of band sets formed as reverse

277 and normal Andersonian regimes. (A) Reverse set of SECBs in Valley of Fire Sate Park

278 (Nevada, USA) seen as limiting red oxidations. (B) Reverse set of CSBs in the Les Crans

279 quarry (Provence, France). (C) Normal SB cluster adjacent to normal fault surface near

280 Goblin Valley State Park (Utah, USA). (D) Normal SB cluster at the vicinity of two fault

281 surfaces in the Boncavaï quarry (Provence, France). (E) Histograms of number of band

282 per meter versus distance along scan lines for various reverse band sets. (F) Same type of

283 histograms as shown in E, for normal band sets. Zones striped in gray mark intervals

284 where the sandstone is not exposed.

285

286 Figure 2. Data set synthesis of reverse (black dots), normal (open dots) and strike-slip

287 (grey dots) band sets plotted as cluster factor versus maximum value of bands per meter.

288 Schemes of synthetic data distribution are shown for different values of Cluster Factor.

289 Band sets are numbered, and references and number of bands per set can be found in

290 supplementary material.

291 
Publisher: GSA

Journal: GEOL: Geology

DOI:10.1130/G37585.1

292 Figure 3. Compiled data of capillary pressure and porosity measured on samples from

293 reverse and normal bands. Squares and dots are for direct and indirect measures,

294 respectively, see supplementary material for method and data references.

295

$296{ }^{1}$ GSA Data Repository item 2015xxx, xxxxxxxx, is available online at

297 www.geosociety.org/pubs/ft2015.htm, or on request from editing@geosociety.org or

298 Documents Secretary, GSA, P.O. Box 9140, Boulder, CO 80301, USA. 


\section{Figure 1}
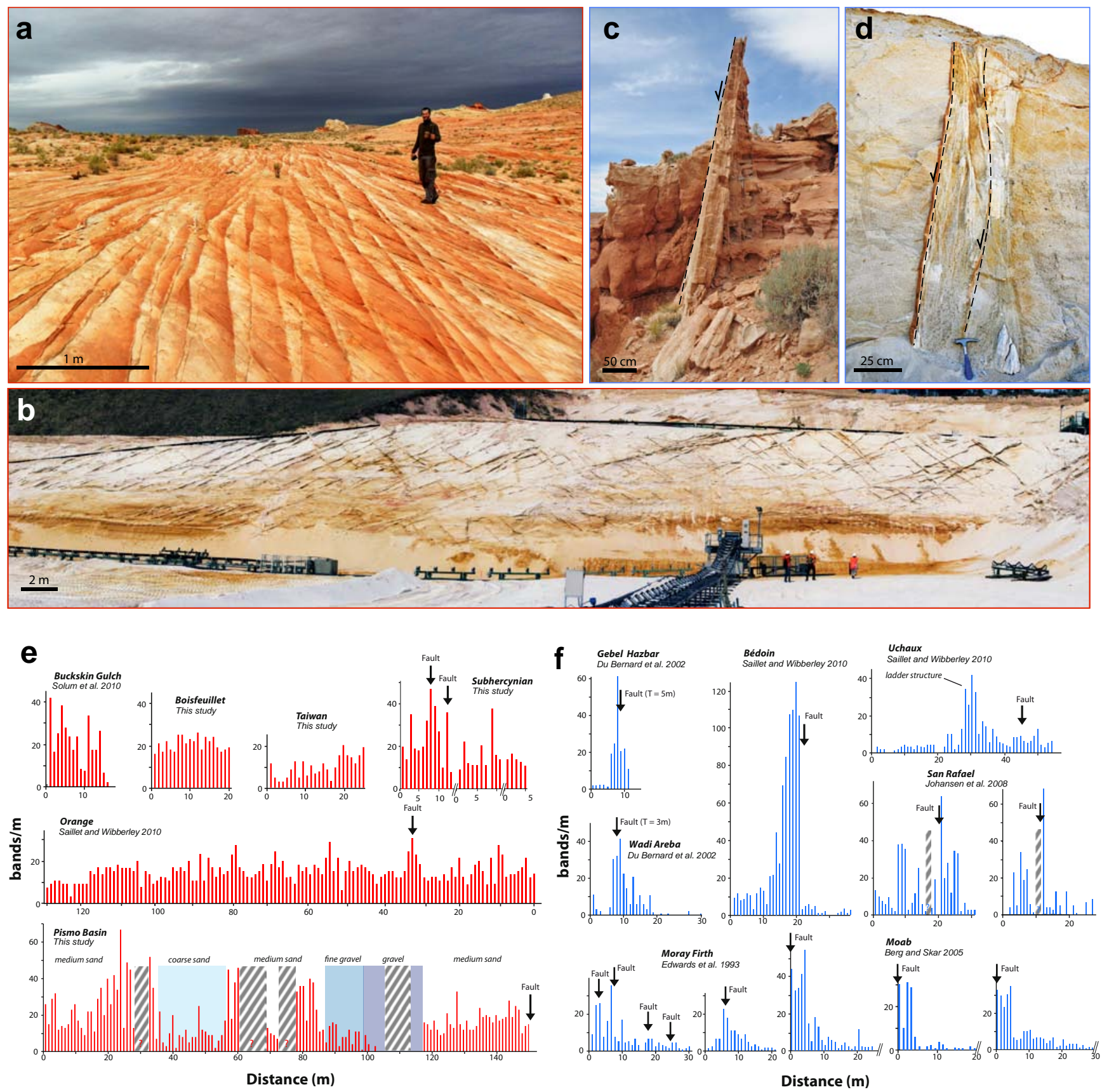

Distance (m)

Moab 2 arg Skar 2005

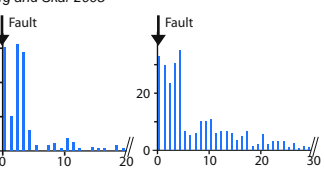


Figure 2

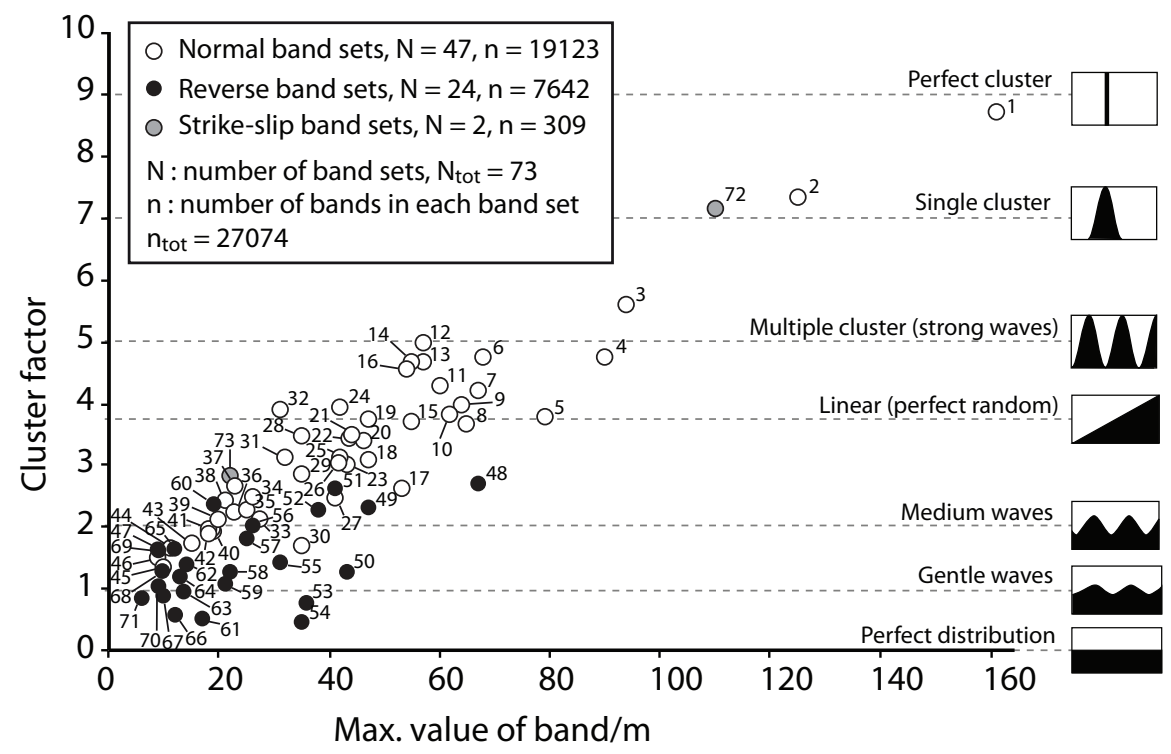


Figure 3

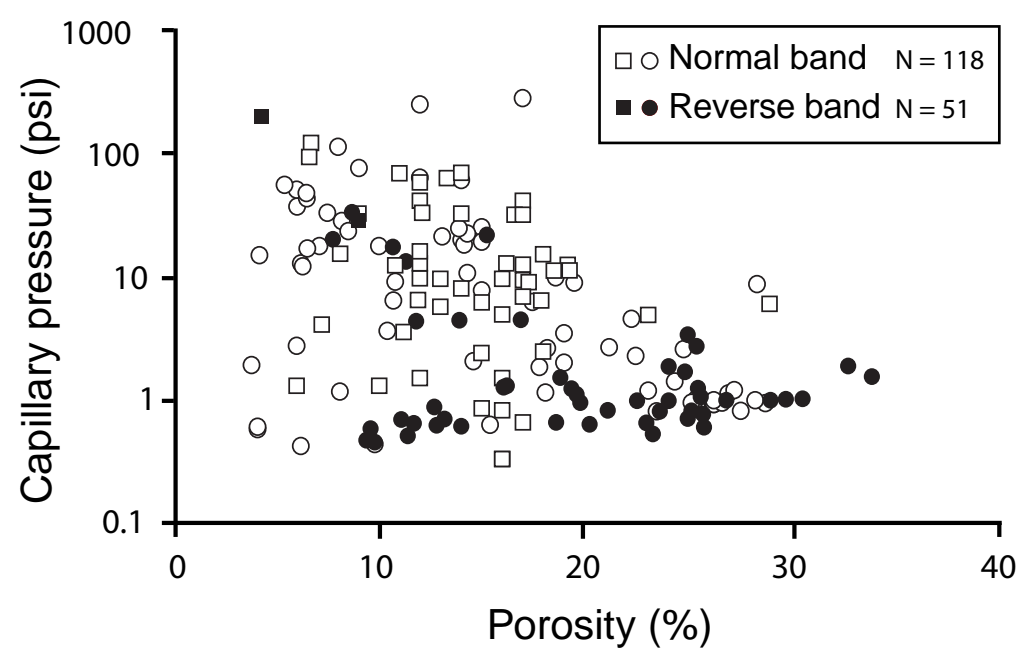




\section{Supplementary material 1: References for data in figure 2}

\subsection{Normal band sets}

1: Delicate Arch (Antonellini and Aydin, 1995), $\mathrm{n}=1710$

2 : Bédoin 3 (Saillet and Wibberley, 2010), $\mathrm{n}=875$

3 : Moab 3 (Davatzes and Aydin, 2003), $\mathrm{n}=855$

4: Moab 2 (Davatzes and Aydin, 2003), $\mathrm{n}=1707$

5 : Gebel Samra (Du Bernard et al., 2002), $\mathrm{n}=951$

6 : San Rafael 1 (Johansen and Fossen, 2008), $\mathrm{n}=244$

7 : Moab 1 (Fossen et al., 2005), $\mathrm{n}=858$

8 : Slickrock (Fossen et al., 2005), $\mathrm{n}=381$

9 : San Rafael 2 (Johansen and Fossen, 2008), $\mathrm{n}=441$

10 : San Rafael 4 (Johansen and Fossen, 2008), $\mathrm{n}=371$

11 : Gebel Hazbar (Du Bernard et al., 2002), $\mathrm{n}=166$

12: Arches Navajo (Antonellini and Aydin, 1994), $\mathrm{n}=428$

13 : San Rafael 5 (Johansen and Fossen, 2008), $\mathrm{n}=127$

14 : Moab 8 (Berg and Skar, 2005), $\mathrm{n}=321$

15 : San Rafael 3 (Johansen and Fossen, 2008), n = 459

16: Arches Morisson (Antonellini and Aydin, 1994), $\mathrm{n}=172$

17 : Wadi Taiba 2 (Beach et al. 1999), $\mathrm{n}=244$

18 : Hidden Canyon 6 (Johansen and Fossen, 2008), n = 690

19: Wadi Taiba 1 (Beach et al. 1999), $\mathrm{n}=1159$

20 : Hidden Canyon 2 (Johansen and Fossen, 2008), $\mathrm{n}=285$

21 : Hidden Canyon 1 (Johansen and Fossen, 2008), $\mathrm{n}=404$

22: Moab Entrada (Antonellini and Aydin, 1994), $\mathrm{n}=151$

23 : Bédoin 1 (Saillet and Wibberley, 2010), $\mathrm{n}=631$

24 : Wadi Areba (Du Bernard et al., 2002), $\mathrm{n}=227$

25 : Uchaux S1 (Saillet and Wibberley, 2010), $\mathrm{n}=403$

26 : Naqb Budra (Du Bernard et al., 2002), $\mathrm{n}=362$

27 : Bédoin 2 (Saillet and Wibberley, 2010), $\mathrm{n}=388$

28 : Moab 7 (Berg and Skar, 2005), $\mathrm{n}=283$

29 : Moray Firth 2 (Edwards et al., 1993), $\mathrm{n}=230$

30 : Gebel Heckma (Du Bernard et al., 2002), $\mathrm{n}=365$

31: Moab 4 (Davatzes and Aydin, 2003), $\mathrm{n}=230$

32 : Moab 5 (Berg and Skar, 2005), $\mathrm{n}=154$

33 : Moab Morisson (Antonellini and Aydin, 1994), $\mathrm{n}=261$

34 : Egypt (Schueller et al., 2013), $\mathrm{n}=110$

35 : Uchaux N2 (Saillet and Wibberley, 2010), $\mathrm{n}=146$

36 : Moray Firth 4 (Edwards et al., 1993), $\mathrm{n}=130$

37 : Golf course (Farrel et al., 2014), $\mathrm{n}=89$

38 : Moray Firth 3 (Edwards et al., 1993), $\mathrm{n}=70$

39: Moab 6 (Berg and Skar, 2005), $\mathrm{n}=195$

40 : Uchaux S2 (Saillet and Wibberley, 2010), $\mathrm{n}=258$

41 : Clashach (Farrel et al., 2014), $\mathrm{n}=854$

42: Valley of Eden (Fowles and Burley, 1994), $n=110$

43 : Moray Firth 1 (Edwards et al., 1993), $n=101$

44 : Hidden Canyon 4 (Johansen and Fossen, 2008), $\mathrm{n}=197$

45 : Uchaux N1 (Saillet and Wibberley, 2010), $\mathrm{n}=165$ 
46 : Hidden Canyon 5 (Johansen and Fossen, 2008), $\mathrm{n}=107$

47 : Hidden Canyon 3 (Johansen and Fossen, 2008), $\mathrm{n}=58$

\subsection{Reverse band sets}

48: Pismo Medium Grain (this study), $\mathrm{n}=1248$

49: Subhercynian 1 (this study), $\mathrm{n}=325$

50 : Montmout (this study), $\mathrm{n}=136$

51 : Buckskin Gulch (Solum et al., 2010), $\mathrm{n}=323$

52: Subhercynian 3 (this study), $\mathrm{n}=68$

53 : Boncavaï (this study), $\mathrm{n}=90$

54 : Sablex (this study), $\mathrm{n}=129$

55 : Orange (Saillet and wibberley, 2010), $\mathrm{n}=3591$

56 : Boisfeuillet (this study), $\mathrm{n}=142$

57: Pismo Coarse Sand (this study), $\mathrm{n}=310$

58: Subhercynian 2 (this study), $\mathrm{n}=96$

59 : Taiwan 2 (this study), $\mathrm{n}=152$

60: Les Crans 2 (this study), $\mathrm{n}=171$

61: Subhercynian 4 (this study), $\mathrm{n}=69$

$62:$ Bollène (this study), $\mathrm{n}=59$

63 : Bagnols (this study), $\mathrm{n}=62$

64 : Taiwan 1 (this study), $\mathrm{n}=121$

65: Les Crans 1 (this study), $\mathrm{n}=141$

66: Mornas (this study), $\mathrm{n}=63$

67: Valley of Fire 1 (this study), $n=35$

68: Roquemaure (this study), $\mathrm{n}=99$

69 : Pismo Gravels (this study), $\mathrm{n}=16$

70 : Valley of Fire 2 (this study), $\mathrm{n}=41$

71 : Muddy Mountains (this study), $\mathrm{n}=40$

\subsection{Strike-slip band system}

72 : Bédoin 4 (this study), $\mathrm{n}=233$

73 : St Michel (this study), $\mathrm{n}=76$

\subsection{References :}

Antonellini, M., Aydin, A., 1994. Effect of faulting on fluid flow in porous sandstones: petrophysical properties, American Association of Petroleum Geologists Bulletin, no. 78, p. 355-377.

Antonellini, M.A., Aydin, A., 1995. Effect of faulting on fluid flow in sandstones, geometry and spatial distribution: American Association of Petroleum Geologists Bulletin, no. 78, p. 642-671.

Beach, A., Welbon, A. I., Brockbank, P. J., McCallum, J. E., 1999, Reservoir damage around faults: Outcrop examples from the Suez Rift: Petroleum Geosciences, v. 5, p. 109-116.

Berg, S. S., and T. Skar, 2005, Controls on damage zone asymmetry of a normal fault zone: Outcrop analysis of a segment of the Moab fault, SE Utah, Journal of Structural Geology, no. 27 , p. $1803-1822$. 
DuBernard, X., Labaume, P., Darcel, C., Davy, P., Bour, O., 2002. Cataclastic slip band distribution in normal fault damage zones, Nubian sandstones, Suez rift, Journal of Geophysical Research, no. 107-B7, p. 2141-2153.

Davatzes, N.C., and Aydin A., 2003. Overprinting faulting mechanisms in high porosity sandstones of SE Utah: Journal of Structural Geology, no. 25, p. 1795-1813.

Edwards, E. H., Becker, A. D., Howell, J. A., 1993. Compartimentalization of an eolian sandstone by structural heterogeneities: Permo- Triassic Hopeman Sandstone, Moray Firth, Scotland, in Characterization of Fluvial and Aeolian Reservoirs, eds., C. P. North and D. J. Prosser, Geological Society [London], Special Publications 73, p. 339- 365.

Farell, N.J.C., Healy, D., Taylor, C.W., 2014. Anisotropy of permeability in faulted porous sandstones, Journal of Structural Geology, No. 63, p. 50-67.

Fossen, H., Johansen, T.E.S., Hesthammer, J., Rotevatn, A., 2005. Fault interaction in porous sandstone and implications for reservoir management; examples from southern Utah, American Association of Petroleum Geologists Bulletin, no. 89, p. 1593-1606.

Fowles, J., Burley, S., 1994. Textural and permeability characteristics of faulted, high porosity sandstones, Marine and Petroleum Geology, no. 11, p. 608-623.

Johansen, T.E.S., Fossen, H., 2008. Internal geometry of fault damage zones in interbedded siliciclastic sediments, in Wibberley, C.A.J., Kurz, W., Imber, J., Holdsworth, R.E. Collettini, C., eds., The internal structure of fault zones: Implications for mechanical and fluid-flow properties, Geological Society [London], Special Publications 299, p. 35-56.

Johansen, T.E.S., Fossen, H., 2008. Internal geometry of fault damage zones in interbedded siliciclastic sediments, in Wibberley, C.A.J., Kurz, W., Imber, J., Holdsworth, R.E. Collettini, C., eds., The internal structure of fault zones: Implications for mechanical and fluid-flow properties, Geological Society [London], Special Publications 299, p. 35-56.

Saillet, E., Wibberley, C.A.J., 2010. Evolution of cataclastic faulting in high-porosity sandstone, Bassin du Sud-Est, Provence, France: Journal of Structural Geology, no. 32, p. 1590-1608.

Schueller, S., Braathen, A., Fossen, H., Tveranger, J., 2013. Spatial distribution of deformation bands in damage zones of extensional faults in porous sandstones: statistical analysis of field data, Journal of Structural Geology, no. 52, p. 148-162. 


\section{Supplementary material 2: Mechanical explanation}

\subsection{Porous sandstone mechanical behaviour and stress paths for contraction and extension}

Mechanical tests in porous sandstones generally show a localized Byerlee-type shear behavior at low to moderate applied mean stresses (relative to $P^{*}$, the maximum means stress supported by the material), and a more distributed compactional/cataclastic behavior at relatively high mean stresses (yield Cap envelope, e.g. Wong and Baud, 2012; Rutter and Glover, 2013) (see Figure 1 in supplementary material). In geologic conditions, for a given initial lithostatic stress state (burial stress path), tectonic contraction increases first the mean stress in the rock, and later the differential stress. This contractional stress path makes the material more probable to yield in a compactional behavior along the Cap envelope (see the red stress path in Figure 1). In contrast, tectonic extension reduces the mean stress with a synchronous differential stress increase, leading the material to fail in a more frictionalshearing Byerlee-type behaviour (see the blue stress path). Details for the calculation of these stress paths are exposed in Soliva et al., 2013.

These expected strong differences both in mechanical behavior and stress path give the basic premises to explain the different types of clustering observed between reverse and normal regimes. Mechanical tests generally show brittle fractures or cataclastic SBs formed in Byerlee condition (e.g. Fortin et al, 2005), which generally allow shear localization and stress relaxation limiting significant band creation outside the shear zone (Schultz and Soliva, 2012). In contrast, cataclastic "compactional" bands (comparable to CSBs, SECBs and PCB observed in the field) form along the yield cap envelope with little or no stress relaxation, keeping the sandstone critically stressed in its volume. This allows subsequent compactional band development and infill into the whole sample. Important differences however rise between mechanical test and nature such as large thickness of SBs clusters observed in the field compared to SBs formed in test. This probably finds explanation in the difference of sample scale and boundary conditions between mechanical test and nature."

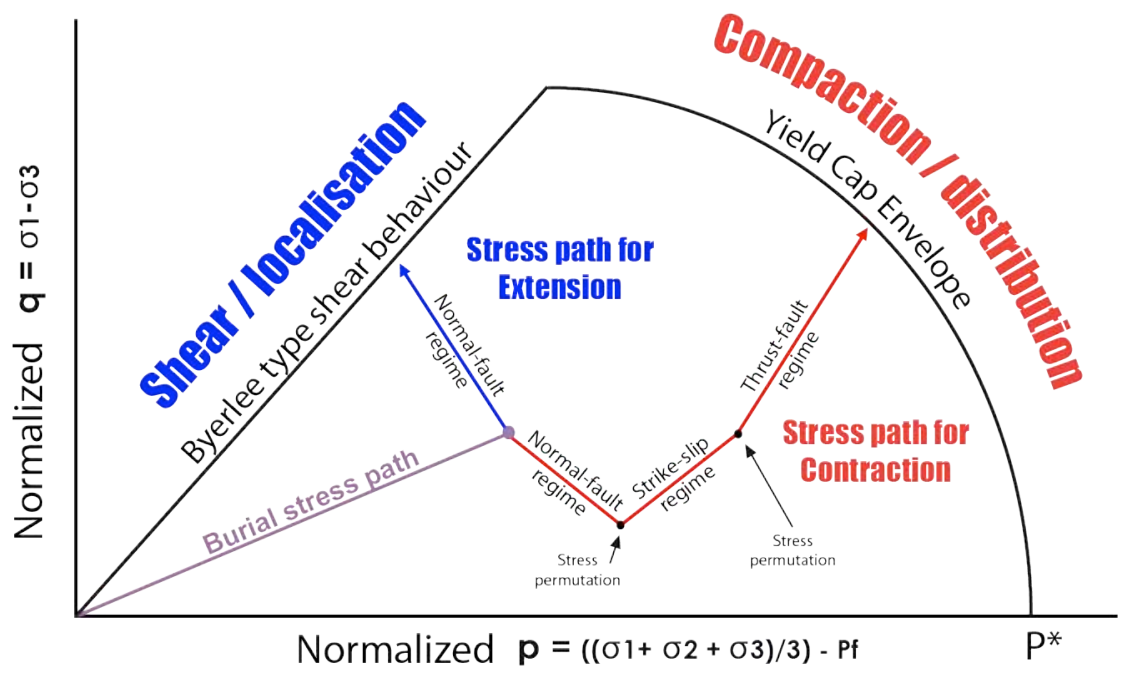

Figure 1. Graph of normalized differential stress $(q)$ and mean stress $(p)$ showing the yield strength envelope for porous sandstones and the burial and tectonic stress path for contraction and extension. Stress path for extension favours shear strain localisation due to a Byerlee type mechanical behaviour, whereas stress path for contraction allows compactional strain distribution due to a yield cap compactional behaviour. 


\subsection{References}

Fortin, J., Shubnel, A., Guégen, Y., 2005. Elastic wave velocities and permeability evolution during compaction of Bleurswiller Sandstone. Int. J. Rock Mech. Min. Sci., 42, 873-889.

Rutter, E.H., Glover, C.T., 2012. The deformation of porous sandstones; are Byerlee friction and the critical state line equivalent? Journal of Structural Geology, no. 44, p. 129-140.

Schultz, R.A, Soliva, R., 2012. Propagation energies inferred from deformation bands in sandstone. International Journal of Fracture, no. 176, p. 135-149, doi:10.1007/s10704-012-9730-2.

Wong, T-f., Baud, P., 2012. The brittle-ductile transition in porous rock: A review: Journal of Structural Geology, no. 44, p. 25-53. 


\section{Supplementary material 3: Capillary Pressure Method}

The capacity for a fluid to pass through a porous media depends on the pressure applied to this fluid. A minimum pressure, called capillary pressure $(P c)$, is necessary for a non-wetting fluid (hydrocarbon, mercury) to displace a wetting fluid (air, water) in a porous network composed of pores and connections (Pittman 1992). In the figure 3, we synthesized direct measures of capillary pressure in apparatus from the following papers: Gibson (1998), Ogilvie and Glover (2001), Tueckmantle et al. (2010), and Torabi et al. (2013). We completed this data set with indirect measures of capillary pressures calculated from porosity, permeability, or pore access radius data described in the following references: Fowles and Burley (1994), Lothe et al. (2002), Al-Hinaï et al. (2008), Aydin and Ahmadov (2009), Sun et al. (2011), Ballas et al. (2013) and Ballas et al. (2014). Methods used for capillary pressure calculation are exposed below (see Torabi et al., 2013 for detailed explanation). Data are classified between structures coming from extensional tectonic regime and contractional tectonic regime. These data are used to reveal the ability of a fault to act as a barrier or conduit to fluid flow (Torabi et al., 2013).

\subsection{Capillary pressure calculated from Mercury Injection-Capillary Pressure (MICP)}

The capillary pressure can be estimated using a graphical method from MICP data (Katz and Thompson, 1986). Because this point is generally difficult to obtain, the Washburn's equation (1921) is generally used to estimate the capillary pressure form MICP data:

$$
P c=\frac{2 \gamma \cos \Phi}{R} \Phi
$$

With: $P c=$ Capillary Pressure $(\mathrm{psi})$

$\gamma=$ Two-phase fluid interfacial tension (480 dynes/cm for Mercury/Air)

$\Phi=$ Contact angle between two-phase fluids and solid (140 ${ }^{\circ}$ for Mercury/Air)

$R=$ Effective pore-access radius $(\mu \mathrm{m})$, corresponding to the apex point on a graph showing Hg saturation/pressure vs Hg saturation (Pittman 1992).

The $P c$ obtained with the equation (1) is converted for a two-phase fluids oil/water using the following equation:

$$
P c(\text { oil/water })=\frac{31}{485} P c(\mathrm{Hg} / \text { air })
$$

\subsection{Capillary pressure from Porosity-Permeability data}

Empirical relationship (3) between porosity, permeability and effective pore-access radius was established from 800 sandstone samples by Pittman (1992).

$$
\log (R)=-0.117+0.475 \log (k)-0.099 \log (n)
$$

With: $\quad R=$ Effective pore-access radius $(\mu \mathrm{m})$

$k=$ Permeability $(\mathrm{mD})$

$n=$ Porosity 
This effective pore-access radius is used in the equation (1) to calculate the capillary pressure.

\subsection{References}

Al-Hinai, S., Fisher, Q.J., Al-Busafi, B., Guise, P., Grattoni, C.A., 2008. Laboratory measurements of the relative permeability of cataclastic fault rocks: an important consideration for production simulation modelling. Marine and Petroleum Geology $25,473-485$.

Aydin, A., Ahmadov, R., 2009. Bed-parallel compaction bands in aeolian sandstone: Their identification, characterization and implications. Tectonophysics 479, 277-284.

Ballas, G., Soliva, R., Sizun, J-P., Fossen, H., Benedicto, A., Skurtveit, E., 2013. Shearenhanced compaction bands formed at shallow burial conditions; implications for fluid flow (Provence, FRANCE). Journal of Structural Geology 47, 3-15.

Ballas, G., Soliva, R., Benedicto, A., Sizun, J-P., 2014. Control of tectonic setting and large-scale faults on the basin-scale distribution of deformation bands in porous sandstone (Provence, France). Marine and Petroleum Geology 55, 142-159.

Fowles, J., Burley, S., 1994. Textural and permeability characteristics of faulted, high porosity sandstones. Marine and Petroleum Geology 11, 608-623.

Gibson, R.G., 1998. Physical character and fluid-flow properties of sandstone-derived fault zones. In: Coward, M.P., Daltaban, T.S., Johnson, H., (Eds.), Structural Geology in Reservoir Characterization. Geological Society, London, Special Publications 127, 83-97.

Katz, A.J., Thompson, A.H., 1986. Quantitative prediction of permeability in porous rock. Physical Review B34, 8179-8181.

Lothe, A.E., Gabrielsen, R.H., Bjørnevoll Hagen, N., Larsen, B.T., 2002. An experimental study of the texture of deformation bands : effects on porosity and permeability of sandstones. Petroleum Geoscience 8, 195-207.

Ogilvie, S.R., Glover, P.W.J., 2001. The petrophysical properties of deformation bands in relation to their microstructure. Earth and Planetary Science Letters 193, 129-142.

Pittman, E.D., 1992. Relationship of Porosity and Permeability to Various Parameters Derived from Mercury Injection-Capillary Pressure Curves for Sandstone. American Association of Petroleum Geologists Bulletin 76, 191-198.

Sun, W., Andrade, J.E., Rudnicki, J.W., Eichhubl, P., 2011. Connecting microstructural attributes and permeability from 3D tomographic images of in situ shear-enhanced compaction bands using multiscale computations. Geophysical Research Letters 38, L10302.

Torabi, A., Fosse, H., Braathen, A., 2013. Insight into petrophysical properties of deformed sandstone reservoirs. American Association of Petroleum Geologists Bulletin 97, 619-637.

Tueckmantel, C., Fisher, Q.J., Knipe, R.J., Lickorish, H., Khalil, S.M., 2010. Fault seal prediction of seismic-scale normal faults in porous sandstone: A case study from the eastern Gulf of Suez rift, Egypt. Marine and Petroleum Geology 27, 334-350.

Washburn, E.W., 1921. Note on a method of determining the distribution of pore sizes in a porous material. Proceeding of the National Academy of Science 7, 115-116. 